\title{
PENGGUNAAN MEDIA GAMBAR DAN MEDIA RADIO PADA PEMBELAJARAN MENULIS DESKRIPSI SISWA KELAS X SMA TUNAS HARAPAN BALARAJA-TANGERANG
}

\author{
Ade Siti Haryanti \\ Email: ade.siti86haryanti@gmail.com
}

\author{
Pendidikan Bahasa dan Sastra Indonesia, Fakultas Keguruan dan Ilmu \\ Pendidikan, Universitas Indraprasta PGRI
}

\begin{abstract}
The purpose of this study is to know the difference between the results of learning to write a description by using the image media and the results of learning to write a description by using radio media grade students X SMA TUNAS HARAPAN Balaraja-Tangerang. This research uses quasi experiment method. Trying to experiment on two learning media without manipulation data. Based on the calculation of data processing has been done, it can be concluded that between the media images and radio media there is no significant difference. This can be proven after testing using $t$ test formula, the average result of the test scores obtained in the class X.1 which in the implementation of learning using the image media reaches the average value 72,4while in class X.2 which in the implementation of learning using the radio media reaches the average value 71 . Of the test results using the formula t arithmetic amount 0,59 an t table 2,074 on the level of trust $5 \%$ and 2,819 on the level of trust $1 \%$ or $0,59 \leq 2,074 \leq 2,819$. This means $t$ count $\leq t$ table meaning not significant. It can be concluded that both media is effectively used in learning to write a description.
\end{abstract}

keywords: teaching of descriptive writing, media of picture, media of radio

\section{Abstrak}

Tujuan penelitian ini adalah untuk mengetahui perbedaan antara hasil pembelajaran menulis deskripsi dengan menggunakan media gambar dan hasil pembelajaran menulis deskripsi dengan menggunakan media radio siswa kelas $\mathrm{X}$ SMA TUNAS HARAPAN Balaraja-Tangerang.Penelitian ini menggunakan metode ekperimen semu, mencoba untuk mengadakan eksperimen terhadap dua buah media pembelajaran tanpa memanipulasi data.Berdasarkan perhitungan pengolahan data yang telah dilakukan, maka dapat diperoleh simpulan yaitu bahwa antara media gambar dan media radio tidak terdapat perbedaan yang signifikan. Hal ini dapat dibuktikan setelah melakukan pengujian dengan menggunakan rumus uji t, yaitu hasil rata-rata nilai tes yang diperoleh di kelas X.1 yang dalam pelaksanaan pembelajarannya menggunakan media gambar mencapi nilai rata-rata 72,4 sedangkan di kelas X.2 yang dalam pelaksanaan pembelajarannya menggunakan media radio mencapai nilai rata-rata 71. Dari hasil pengujian menggunakan rumus $\mathrm{t}$ hitung, diperoleh hasil $\mathrm{t}$ hitung sebesar 0,59 dan $t$ tabel 2,074 pada taraf kepercayaan $5 \%$, dan 2,819 pada taraf kepercayaan $1 \%$ atau $0,59 \leq 2,074 \leq$ 2 , 819. Hal ini berarti $\mathrm{t}$ hitung $\leq \mathrm{t}$ tabel artinya tidak signifikan.Maka dapat disimpulkan bahwa kedua media tersebut efektif digunakan dalam pembelajaran menulis deskripsi.

kata kunci: pembelajaran menulis deskripsi, media gambar, media radio

\section{PENDAHULUAN}

Mempelajari bahasa sebagai
objek ilmu bertujuan untuk memperoleh pengetahuan teoretis mengenai bahasa. Belajar berbahasa ialah belajar menggunakan bahasa. Belajar bahasa pada hakikatnya adalah belajar berkomunikasi. Karena dengan pembelajaran bahasa diharapkan membantu peserta didik mengenal dirinya, budayanya, dan budaya orang lain. Maka dari itu bahasa memiliki peran sentral dalam

\section{4 | Jurnal Kredo} Vol. 1 No. 2 April 2018 perkembangan intelektual, sosial, dan emosional peserta didik dan merupakan penunjang keberhasilan dalam mempelajari semua bidang studi. Hal ini relevan dengan Permendiknas No 22 Tahun 2006 tentang standar isi yang menyatakan bahwa tujuan mata pelajaran bahasa Indonesia adalah, menghargai dan membanggakan sastra Indonesia sebagai khazanah budaya dan intelektual manusia Indonesia.

Proses belajar mengajar akan berjalan dengan baik dan efektif jika 
bahasa yang digunakan benar-benar berfungsi dalam proses interaksi antara guru dengan siswa. Salah satu keterampilan yang harus dimiliki siswa yaitu keterampilan menulis. Keterampilan menulis merupakan bagian dari keterampilan yang tidak dapat dipisahkan dari seluruh proses belajar yang dialami oleh siswa. Keterampilan menulis dalam pemerolehannya dan pemakaiannya dianggap sebagai keterampilan yang sangat sukar dan sulit serta kompleks (Akhadiah, 1989: 2).

Kita sering mendengar istilah menulis atau mengarang, mungkin bayangannya terkait pada sesuatu yang tidak menarik, menjemukan, dan bahkan mebosankan. Pada kenyataannya, siswa yang terampil menulis tidak akan mengalami kesulitan dalam menyelesaikan tugas-tugas sekolah

seperti menyusun makalah, laporan tertulis, serta membuat karangan. Namun masih banyak siswa yang menganggap bahwa kegiatan menulis merupakan suatu beban berat. Anggapan itu timbul karena kegiatan menulis memang meminta banyak tenaga, waktu, serta perhatian yang sungguh-sunggguh.

Pembelajaran menulis atau mengarang dibagi menjadi empat jenis karangan yaitu, karangan narasi, deskripsi, eksposisi, dan argumentasi.Karangan Deskripsi merupakan bentuk tulisan yang bertujuan memperluas pengetahuan dan pengalaman pembaca dengan jalan melukiskan hakikat objek yang sebenarnya.Karangan Narasi merupakan suatu bentuk tulisan yang berusaha menciptakan, mengisahkan, merangkaikan tindak tanduk perbuatan manusia dalam sebuah peristiwa secara kronologis atau yang berlangsung dalam suatu kesatuan
waktu.karanganArgumentasi

merupakan tulisan yang bertujuan untuk meyakinkan pembaca agar menerima atau mengambil suatu doktrin, sikap, dan tingkah laku tertentu. Dan karangan Eksposisi merupakan wacana yang bertujuan untuk memberi tahu, mengupas, menguraikan, atau menerangkan sesuatu, (Finoza, 2008: 233-243). Kajian yang akan dibahas dalam penelitian ini adalah menulis karangan deskripsi.

Tidak semua orang mampu menulis karangan deskripsi dengan baik.Faktanya, berdasarkan hasil observasi dengan beberapa guru bidang studi bahasa dan sastra Indonesia di SMA TUNAS HARAPAN Balaraja, masih banyak siswa yang menemui masalah dalam pembelajaran menulis karangan deskripsi. Hal tersebut terjadi karena rendahnya pengetahuan teori menulis, dan sedikitnya guru yang menggunakan media dalam proses belajar mengajar.

Inilah salah satu alasan bagi peneliti, bahwa kurangnya pengetahuan dalam menulis menyebabkan siswa sulit untuk menuangkan ide dan pokok pikiran dalam bentuk tulisan. Salah satu cara alternatif yaitu dengan menggunakan media dalam proses belajar mengajar. Yang bertujuan agar tercipta suasana yang nyaman dan tidak membosankan di dalam kelas, dan ketidakjelasan suatu materi akan dibantu oleh media sebagai perantara pembelajaran.

Sudah banyak media yang digunakan dalam proses belajar mengajar, namun dalam hal ini peneliti ingin memberikan sesuatu kepada siswa dengan menggunakan media yang dekat dengan kesaharian siswa, yaitu media gambar dan 
media radio. Selain itu peneliti juga ingin mengetahui seberapa besar persamaan dan perbedaan antara hasil yang diperoleh siswa dalam pembelajaran menulis karangan deskripsi dengan menggunakan media gambar, dengan pembelajaran menulis karangan deskripsi dengan menggunakan media radio. Sehingga peneliti dapat mengetahui media manakah yang paling efektif digunakan dalam pembelajaran menulis karangan deskripsi.

Dalam hal ini, gambar yang disajikan adalah dalam bentuk rangkaian gambar yang sederhana berisi pesan secara ringkas, dan informasi yang diperdengarkan melalui media radio yaitu berupa rangkaian cerita yang jelas dan sederhana. Oleh karena itu, permasalahan ini menarik untuk diteliti. Salah satu alasannya adalah, bahwa rendahnya pengetahuan menulis karangan deskripsi membuat siswa sulit untuk mengungkapkan tentang apa yang telah ia lihat, dengar dan rasakan. Maka dari itu, dalam penelitian ini akan menjelaskan permasalahan dengan judul: "Penggunaan Media Gambar dan Media Radio pada Pembelajaran Menulis Deskripsi Siswa Kelas X SMA TUNAS HARAPAN BalarajaTangerang.

Tujuan penelitian ini adalah ingin mengetahui ada tidaknya perbedaan antara hasil pembelajaran menulis deskripsi dengan menggunakan media gambar dan hasil pembelajaran menulis deskripsi dengan menggunakan media radio siswa kelas $X$ SMA TUNAS HARAPAN Balaraja-Tangerang.

Hipotesis dalam penelitian ini adalah Terdapat perbedaan antara hasil pembelajaran menulis deskripsi dengan menggunakan media gambar dengan hasil pembelajaran menulis dekripsi dengan menggunakan media radio siswa kelas X SMA TUNAS HARAPAN Balaraja-Tangerang.Tidak terdapat perbedaan antara hasil pembelajaran menulis deskripsi dengan menggunakan media gambar dengan hasil pembelajaran menulis dekripsi dengan menggunakan media radio siswa kelas $\mathrm{X}$ SMA TUNAS HARAPAN Balaraja-Tangerang.

Kajian yang relevan dengan penelitian ini adalah, penelitian yang dilakukan oleh Indah Mustikasari.Dalam penelitiannya Indah Mustikasari menelaah tentang "Pengaruh Penggunaan Tape Recorder terhadap Pembelajaran Menyimak Berita pada Siswa Kelas VII SMP PGRI Ciruas".Indah Mustikasari dalam penelitiannya menggunakan media Tape Recorder untuk kelas eksperimen, sedangkan di kelas kontrol tanpa menggunakan bantuan media. Hasil dari penelitian yang dilakukan oleh Indah Mustikasari yaitu diperoleh hasil $t_{\text {hitung }}$ sebesar 3,363 dengan $t_{\text {tabel }}$ adalah 1,71 dengan drajat kebebasan $(\mathrm{N}-2), 6-2=24$. Sesuai dengan kaidah pengkajian apabila $t_{\text {hitung }}$ lebih besar atau sama dengan $t_{\text {tabel, }}$ maka Ho artinya signifikan. Berdasarkan hasil pengujian baik analisis korelasi ataupun $t_{\text {hitung, maka dapat }}$ dinyatakan bahwa ada pengaruh yang signifikan antara penggunaan media. Tape Recorder pada pembelajaran menyimak berita siswa kelas VII A dan B SMP PGRI Ciruas -Serang.

Sedangkan dalam penelitian ini, peneliti menggambil judul "Penggunaan Media Gambar dan Media Radio pada Pembelajaran Menulis Deskripsi Siswa Kelas X SMA TUNAS HARAPAN BalarajaTangerang". Adapun yang peneliti

\section{6 | Jurnal Kredo}

Vol. 1 No. 2 April 2018 
lakukan yaitu, menggunakan media gambar di kelas X.1 dan di kelas X.2 menggunakan media radio dalam pembelajaran menulis karangan deskripsi, sehingga terlihat perbedaan antara hasil pembelajaran menulis deskripsi dengan menggunakan media gambar, dengan hasil pembelajaran menulis deskripsi dengan menggunakan media radio.

Persamaan antara penelitian ini dengan penelitian yang dilakukan oleh Indah Mustikasari adalah keduanya sama-sama meneliti penggunaan media dalam pendidikan dan pengaruhnya terhadap proses pembelajaran. Dan memiliki tujuan yang sama, yaitu ingin mengetahui keberhasilan penggunaan media terhadap kegiatan pengajaran.

\section{KAJIAN TEORI}

Pembelajaran adalah belajar. Dalam arti sempit pembelajaran diartikan sebagai suatu proses atau cara yang dilakukan agar seseorang dapat melakukan kegiatan belajar, sedangkan belajar adalah suatu proses perubahan tingkah laku, karena interaksi individu dengan lingkungan dan pengalaman (Zainal, 2009: 10).

Berdasarkan dari pengertian di atas, maka dapat disimpulkan bahwa pembelajaran menulis adalah suatu proses keterampilan berbahasa yang harus dimiliki siswa, yang bertujuan agar terjadi perubahan pada diri siswa yang tadinya tidak tahu menjadi tahu. Selain itu juga dengan pembelajaran menulis siswa diharapkan mampu menyusun atau merangkai kata-kata sebagai pengutaraan pikiran, parasaan, pengkhayalan, serta pengalaman yang dimilikinya, dalam bentuk tulisan yang nantinya dapat

dimengerti dan dipahami oleh pembaca.

Begitu banyak jenis tulisan yang kita ketahui, baik tulisan yang berbantuk cerita pendek, puisi, berita, surat, dan lain-lain. Berbagai jenis tulisan dengan gaya bahasa yang berbeda-beda, tetapi semua jenis tulisan tersebut bila diklasifikasikan kedalam ciri-ciri yang sama, maka dapat dibagi menjadi empat jenis yaitu, narasi, eksposisi, deskripsi, dan argumentasi.

Kata deskripsi berasal dari kata latindescribere yang berarti menulis tentang, atau mebeberkan sesuatu hal. Sebaliknya kata deskripsi dapat diterjemahkan menjadi pemerian, yang berasal dari kata perimemerikan yang berarti "melukiskan sesuatu hal".

Menurut Semi (2007: 66) deskripsi ialah tulisan yang tujuannya untuk memberikan rincian atau detil tentang objek, sehingga dapat memberi pengaruh pada emosi dan menciptakan imajinasi pembaca bagaikan melihat, mendengar, atau merasakan langsung apa yang disampaikan penulis.

Karangan deskripsi merupakan fotokopi objek yang digambarkan dalam bentuk tulisan. Seakan-akan pembaca merasakan sendiri apa yang penulis ceritakan. Deskripsi menggambarkan tentang sesuatu yang dapat dilihat, dengar, dan rasakan.Pada umumnya jenis karangan deskripsi adalah berupa alam, benda, tempat, suasana, dan manusia.

\begin{tabular}{lrr}
\multicolumn{1}{c}{ Dalam } & \multicolumn{1}{c}{ karangan } & deskripsi \\
penulis memindahkan & kesan- \\
kesannya, memindahkan hasil & mengamatan dan perasaannya kepada \\
pengara pembaca, ia menyampaikan \\
para pand \\
sifat dan semua perincian wujud
\end{tabular}


yang dapat ditemukan pada objek tersebut. Sasaran yang ingin dicapai oleh seorang penulis deskripsi adalah menciptakan atau memungkinkan tarciptanya daya khayal atau imajinasi pembaca, seolah-olah mereka melihat sendiri objek tadi secara keseluruhan sebagai yang dialami secara fisik oleh penulisnya (Keraf, 1982: 93).

Karangan deskripsi dituntut untuk dapat menimbulkan daya khayal pembaca, dan dapat menyampaikan kesan seperti yang dirasakan oleh penulisnya. Karangan deskripsi diusahakan membuat seseorang pembaca merasakan suatu peristiwa seolah-olah meraka melihat, mendengar, dan merasakan secara langsung apa yang penulis ceritakan dalam bentuk tulisan.

Dari pengertian karangan deskripsi di atas, maka dapat disimpulkan bahwa karangan atau tulisan deskripsi adalah, karangan yang menggambarkan atau melukiskan berdasarkan kesan dari pengamatan, perasaan dan pengalaman penulisnya. Sehingga pembaca dituntut untuk dapat berimajinasi seolah-olah mereka melihat, mendengar dan merasakan apa yang penulis lukisan dalam sebuah karangan.

Media

adalah

perantara/pengantar dari pengirim ke penerima pesan (Sadiman, 2006: 8). Dalam proses belajar mengajar kehadiran media mempunyai arti yang cukup penting, karena dengan kegiatan tersebut ketidak jelasan bahan yang disampaikan dapat dibantu dengan menghadirkan media sebagai perantara.

Dengan menggunakan media, guru merasa dibantu dalam proses belajar mengajar, selain itu siswa juga marasa nyaman dan tidak

18 | Jurnal Kredo Vol. 1 No. 2 April 2018 membosankan di dalam kelas sehingga siswa dapat memahami materi yang telah diajarkan. Pada saat ini, banyak sekali media yang dapat digunakan dalam pembelajaran, yaitu media audio, media visual, dan media audiovisual. Salah satu contoh media yang dapat digunakan dalam pembelajaran adalah gambar dan radio.

Menurut Hamzah (1985: 26) gambar/foto termasuk ke dalam media visual. Media ini berfungsi untuk menyalurkan pesan dari penerima sumber ke penerima pesan. Pesan yang akan disampaikan kedalam simbol-simbol komunikasi visual, simbol tersebut perlu dipahami dengan benar, artinya agar proses penyampaian pesan dapat berhasil dengan baik dan tidak menimbulkan kesalahan.

Media gambar sangat mengandalkan indera penglihatan. Maka dari itu, jika seorang guru ingin menggunakan media gambar maka jumlah siswa pun harus dibatasi, agar siswa dapat melihat gambar dengan jelas. Setelah dijelaskan tentang pengertian maupun kelamahan dan kelabihan media gambar di atas, maka selain itu masih banyak media yang dapat digunakan dalam pembelajaran, salah satunya adalah media radio.

Radio termasuk ke dalam media audio, yang merupakan salah satu media elektronik yang mengalami perkembangan semakin pesat yang digunakan dalam pengajaran. Media audio dapat digunakan dalam semua fase pembelajaran mulai dari pengantar atau pembukaan ketika memperkenalkan topik bahasan sampai kepada evaluasi hasil belajar siswa (Arsyad, 2007: 149).

Dari pengertian di atas maka dapat disimpulkan bahwa, 
pembelajaran dengan menggunakan media radio siswa diharapkan dapat meningkatkan hasil belajar, karena media radio dapat menimbulkan daya imajinasi siswa berdasarkan indera pendengaran. Media radio ini pun dapat diputar kembali yang memungkinkan akan terjadi perbaikan dalam proses pengajaran.

Penggunaan media radio (tape recorder), memerlukan anggaran terencana, karena dalam pelaksanaannya dibutuhkan media pendukung lainnya.Selain itu guru dituntut untuk terampil dalam menggunakan media tersebut.

\section{METODE PENELITIAN}

Metode memiliki kedudukan yang sangat penting dalam kegiatan ilmiah pada setiap disiplin ilmu. Metode dapat dilakukan pembenaran/penolakan hipotesis serta penemuan asas-asas yang mengatur keberadaan objek sasaran disiplin ilmu itu sendiri. Dengan kata lain, sulit dibayangkan tercapainya tujuan masing-masing disiplin ilmu itu tanpa memahami asas-asas yang menandai keberadaan objek sasarannya tanpa metode (Mahsun, 2005: 271). Untuk tercapainya tujuan penelitian, maka dari itu dalam penelitian ini menggunakan metode eksperimen.

Berdasarkan jenisnya maka metode eksperimen dibagi atas dua yaitu, penelitian ekperimen sungguhan (true experimental) dan penelitian eksperimen semu (quasi experimental).Metode eksperimen sungguhan dalam penelitiannya menyelidiki kemungkinan sebabakibat dengan desain di mana secara nyata ada kelompok perlakuan dan kelompok kontrol dan membandingkan hasil perlakuan dengan kontrol secara ketat.Sedangkan metode eksperimen semu dalam penelitiannya, peneliti mengadakan percobaan sungguhan di mana tidak mungkin mengadakan kontrol/memanipulasi semua variabel yang relevan (Nazir, 2005: 73).

Dalam pemerolehan data, penelitian ini menggunakan metode ekperimen semu.Dengan mengadakan eksperimen terhadap dua buah media pembelajaran tanpa memanipulasi data. Yang akan dilakukan adalah untuk mengetahui perbedaan antara hasil pembelajaran menulis deskripsi dengan menggunakan media gambar, dengan hasil pembelajaran menulis deskripsi dengan menggunakan media radio Siswa Kelas X SMA TUNAS HARAPAN Balaraja-Tangerang.

\section{Teknik Pengumpulan Data}

1. Studi Pustaka

Studi pustaka digunakan untuk mencari dan mengkaji dasardasar teoritis, yang erat kaitannya dengan masalah yang diteliti dan untuk memperoleh informasi yang berguna bagi landasan teoretis bahan rujukan penelitian.

2. Uji Coba

Uji coba dilakukan oleh guru pada saat melaksanaan pembelajaran menulis karangan deskripsi dengan menggunakan media gambar dan media radio.

3. Tes tertulis

Tes merupakan serentetan pertanyaan/latihan/alat yang digunakan untuk mengukur keterampilan, pengetahuan intelegensi, kemampuan atau bakat yang dimiliki oleh individu atau kelompok (Suharsimi, 2006: 150).Penelitian ini menggunakan tes tertulis, tes yang dimaksud adalah tes menulis deskripsi 
dengan menggunakan media gambar di kelas X.1, dan tes menulis deskripsi dengan menggunakan media radio di kelas X.2.

\section{Teknik Pengolahan Data}

Agar diperoleh kesimpulan atas penelitian yang dilakukan dan menghasilkan data yang akurat perlu dilaksanakan analisis data.Penelitian ini menggunakan teknik analisis data dengan rumus Uji tsebagai berikut.

$\mathrm{t}_{\mathrm{o}}=\frac{M_{1}-M_{2}}{\sqrt{\left(\frac{\sum x_{1}^{2}+\Sigma x_{2}^{2}}{N_{1}+N_{2}-2}\right)\left(\frac{N_{1}}{N_{1}}+\frac{N_{2}}{N_{2}}\right)}}$

Keterangan:

$\mathrm{t}_{\mathrm{o}}=\mathrm{t}_{\text {hitung }} \mathrm{t}_{\text {observasi }}$

$\mathrm{M}_{1}=$ rata-rata/mean $\mathrm{X}_{1}$

$\mathrm{M}_{2}=$ rata-rata/mean $\mathrm{X}_{2}$

$\mathrm{x}_{1}{ }^{2}=$ kuadrat selisih antara $\mathrm{X}_{1}-X$

$\mathrm{x}_{2}{ }^{2}=$ kuadrat selisih antara $\mathrm{X}_{2}-X$

$\mathrm{N}=$ Number of Cases (banyak sampel)

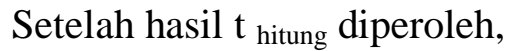
maka langkah selanjutnya yaitu menghitung $\mathrm{t}_{\text {tabel }}$ dengan rumus degrees of freedom d.f $=(\mathrm{N}-2)$. Hasil dari $t_{\text {tabel }}$ tersebut dapat dilihat dalam tabel terlampiran, untuk signifikansi pada á $=0,05$ dan signifikansi pada á = 0,01 (Arikunto, 2006: 363). Hasil dari $t_{\text {hitung }}$ dan $t_{\text {tabel }}$ untuk mengetahui hipotesis diterima atau ditolak.

\section{Populasi dan Sampel Penelitian}

\section{Populasi}

Populasi adalah keseluruhan objek penelitian (Arikunto 2006: 130). Berdasarkan pengertian di atas, sasaran yang akan dijadikan subjek dalam penelitian ini adalah seluruh siswa kelas X SMA TUNAS

20 | Jurnal Kredo

Vol. 1 No. 2 April 2018
HARAPAN Balaraja yang berjumlah 99 orang dalam 4 kelas.

Populasi Siswa Kelas X SMA TUNAS HARAPAN Balaraja

\begin{tabular}{|l|l|l|l|l|}
\hline No & Kelas & $\begin{array}{l}\text { Laki- } \\
\text { laki }\end{array}$ & Perempuan & Jumlah \\
\hline 1 & X.1 & 15 & 9 & 24 \\
\hline 2 & X.2 & 12 & 12 & 24 \\
\hline 3 & X.3 & 15 & 10 & 25 \\
\hline 4 & X.4 & 11 & 15 & 26 \\
\hline & Jumlah & 53 & 46 & 99 \\
\hline
\end{tabular}

\section{Sampel}

Sampel adalah bagian dari sebuah populasi, bagian mana memiliki segala sifat utama populasi. Sampel ialah sebagain atau wakil populasi yang diteliti (Arikunto: 2006: 131). Sampel dalam penelitian ini diambil sebanyak dua kelas. Kelas X.1 dengan jumlah siswa 24 orang ditentukan sebagai kelas eksperimen dengan media gambar, dan kelas X.2 dengan jumlah 24 orang ditentukan sebagai kelas eksperimen dengan media radio. Adapun teknik yang diambil dalam penelitian ini adalah teknik acak (random sampling), dengan alasan untuk menghindari pengambilan sampel yang bersifat subjektif.

\section{HASIL DAN PEMBAHASAN}

Hasil pembelajaran menulis deskripsi diperoleh dari kelas X.1 sebagai kelas yang dilakukan eksperimen media gambar.Menganalisis hasil kerja siswa dengan menggunakan kriteria penilaian 50 sampai dengan 100 bagi siswa yang menulis deskripsi. Dari 24 siswa mengikuti tes maka, terdapat nilai 95 sebanyak 1 siswa, nilai 86 sebanyak 1 siswa, nilai 81 sebanyak 4 siswa, nilai 75 sebanyak 1 siswa, nilai 72 sebanyak 3 siswa, nilai 70 sebanyak 5 siswa. 
Berdasarkan perhitungan di atas, diperoleh nilai hasil pembelajaran menullis deskripsi dengan menggunakan media gambar yang diselenggarakan di kelas X.1 dengan nilai rata-rata 72,4. Artinya hasil pembelajaran tersebut telah mencapai tujuan yang diharapkan.Adapun analisis data sebagai berikut.

$$
\begin{aligned}
\text { Nilai rata-rata } & =\frac{\text { Jumlah nilai }}{\text { Jumlah siswa }} \\
& =\frac{1739}{24} \\
& =72,4
\end{aligned}
$$

Hasil pembelajaran menulis deskripsi diperoleh dari kelas X.1 sebagai kelas yang dilakukan eksperimen media radio.Menganalisis hasil kerja siswa dengan menggunakan kriteria penilaian 50 sampai dengan 100 bagi siswa yang menulis deskripsi. Dari 24 siswa mengikuti tes maka, terdapat nilai 90 sebanyak 1 siswa, nilai 86 sebanyak 1 siswa, nilai 81 sebanyak 2 siswa, nilai 77 sebanyak 3 siswa, nilai 72 sebanyak 4 siswa, nilai 70 sebanyak 2 siswa, nilai 68 sebanyak 4 siswa, nilai 65 sebanyak 3 siswa, nilai 63 sebanyak 1 siswa, nilai 61 sebanyak 1 siswa, nilai 59 sebanyak 2 siswa.

Berdasarkan perhitungan di atas, diperoleh nilai tentang hasil pembelajaran menullis deskripsi dengan menggunakan media radio yang diselenggarakan di kelas X.2 dengan nilai rata-rata 71. Artinya hasil pembelajaran tersebut telah mencapai tujuan yang diharapkan.Adapun analisis data sebagai berikut.

$$
\begin{aligned}
\text { Nilai rata-rata } & =\frac{\text { Jumlah nilai }}{\text { Jumlah siswa }} \\
& =\frac{1706}{24} \\
& =71
\end{aligned}
$$

\section{Uji Perbedaan dengan rumus uji t}

Untuk menjawab hipotesis pada bab 1, dijelaskan bahwa terdapat perbedaan antara hasil pembelajaran menulis deskripsi dengan menggunakan media gambar, dengan hasil pembelajaran menulis deskripsi

\begin{tabular}{|c|c|c|c|c|}
\hline $\begin{array}{c}\text { No. } \\
\text { Responden }\end{array}$ & $\mathrm{X}_{1}$ & $\mathrm{X}_{2}$ & $\mathrm{X}_{1}^{2}$ & $\mathrm{X}_{2}{ }^{2}$ \\
\hline 1 & 72 & 70 & 5184 & 4900 \\
\hline 2 & 63 & 65 & 3969 & 4225 \\
\hline 3 & 72 & 81 & 5148 & 6561 \\
\hline 4 & 72 & 68 & 5148 & 4624 \\
\hline 5 & 70 & 68 & 4900 & 4624 \\
\hline 6 & 70 & 65 & 4900 & 4225 \\
\hline 7 & 70 & 63 & 6561 & 3969 \\
\hline 8 & 81 & 81 & 4624 & 6561 \\
\hline 9 & 68 & 72 & 4624 & 5184 \\
\hline 10 & 68 & 77 & 4624 & 5929 \\
\hline 11 & 68 & 72 & 4624 & 5184 \\
\hline 12 & 68 & 65 & 4624 & 4225 \\
\hline 13 & 68 & 77 & 4624 & 5929 \\
\hline 14 & 70 & 59 & 4900 & 3481 \\
\hline 15 & 86 & 61 & 7396 & 3721 \\
\hline 16 & 81 & 77 & 6561 & 5929 \\
\hline 17 & 70 & 72 & 4900 & 5184 \\
\hline 18 & 95 & 86 & 9025 & 7396 \\
\hline 19 & 75 & 68 & 5625 & 4624 \\
\hline 20 & 63 & 70 & 3969 & 4900 \\
\hline 21 & 68 & 68 & 4624 & 4624 \\
\hline 22 & 59 & 59 & 3481 & 3481 \\
\hline 23 & 81 & 72 & 6561 & 5184 \\
\hline 24 & 81 & 90 & 6561 & 8100 \\
\hline Jumlah 24 & $\begin{array}{l}\sum X_{1}= \\
1739\end{array}$ & $\begin{array}{c}\sum X_{2}= \\
1706\end{array}$ & $\begin{array}{l}\sum X_{I}^{2}= \\
127505\end{array}$ & $\begin{array}{l}\sum X_{2}^{2}= \\
122764\end{array}$ \\
\hline
\end{tabular}
dengan menggunakan media radio pada siswa kelas X SMA TUNAS HARAPAN Balaraja-Tangerang. selanjutnya untuk memudahkan perhitungan dibuat tabel bantu pada halaman berikut:

\section{TABEL BANTUAN MENCARI T-Test}

Dari data di atas, dapat diperoleh hasil $\sum \mathrm{X}_{1}$ sebesar $1739, \sum \mathrm{X}_{2}$ sebesar 1706, $\sum X_{1}^{2}$ sebesar 127505, dan $\sum \mathrm{X}_{2}^{2}$ sebesar 122764.Agar diperoleh simpulan atas penelitian yang dilakukan, dan menghasilkan data yang akurat perlu dilaksanakan analisis data. Dalam penelitian ini, 
digunakan teknik analisis data dengan rumus uji $t$, tetapi sebelumnya mencari mean dan standar deviasi terlebih dahulu dengan rumus sebagai berikut.

1. Mencari masing-masing mean yaitu $\mathrm{M}_{1}$ dan $\mathrm{M}_{2}$ dengan rumus:

$$
\begin{aligned}
& M_{1}=\frac{\Sigma \mathrm{X}_{1}}{\mathrm{~N}} \mathrm{dan} M_{2}=\frac{\Sigma \mathrm{X}_{2}}{\mathrm{~N}} \quad \text { sehingga } \\
& M_{1}=\frac{1739}{24}=72,45 \mathrm{dan} \\
& M_{2}=\frac{1706}{24}=71,08
\end{aligned}
$$

2. Mencari deviasi $X_{1}$ Dan $X_{2}$

$$
\begin{aligned}
M_{1} \rightarrow \sum x_{1}{ }^{2} & =\sum x_{1}{ }^{2}-\frac{\left(\sum x_{1}\right)^{2}}{N} \\
& =127505-\frac{(1739)^{2}}{24} \\
& =127505-\frac{3024121}{24} \\
= & 127505-126005,04 \\
= & 1499,96 \\
M_{2} \rightarrow \sum x_{2}{ }^{2} & =\sum x_{2}{ }^{2}-\frac{\left(\sum x_{2}\right)^{2}}{N} \\
& =122764-\frac{(1706)^{2}}{24} \\
& =122764-\frac{2910436}{24} \\
= & 122764-121268,16 \\
= & 1495,84
\end{aligned}
$$

Dengan diperolehnya mean $M_{1}$ sebesar 72,45dan $M_{2}$ sebesar 71,08 dan standar deviasi $X_{1}$ dan $X_{2}$, maka selanjutnya mencari nilai t-test atau $t_{0}$ dengan rumus sebagai berikut.

22 | Jurnal Kredo

Vol. 1 No. 2 April 2018

$$
t_{0}=\frac{M_{1}-M_{2}}{\sqrt{\left(\frac{\sum x_{1}^{2}+\Sigma x_{2}^{2}}{N_{1}+N_{2}-2}\right)\left(\frac{N_{1}}{N_{1}}+\frac{N_{2}}{N_{2}}\right)}}
$$

$$
\begin{aligned}
& t_{0} \frac{72,45-71,08}{\left.\frac{199,96+1495,84}{24+24-2}\right)\left(\frac{24}{24}+\frac{24}{24}\right)} \\
& t_{0}=\frac{1,37}{\sqrt{\left(\frac{2995,8}{46}\right)\left(\frac{48}{576}\right)}}
\end{aligned}
$$

$$
t_{0}=\frac{1,37}{\sqrt{\left(\frac{143798,4}{26496}\right)}}
$$

$$
t_{0}=\frac{1,37}{\sqrt{5,4}}
$$

$t_{0}=\frac{1,37}{2,3}$

$t_{0}=0,59$

Berdasarkan perhitungan tersebut di atas, diperoleh nilai $\mathrm{t}$ hitung sebesar 0,59. Untuk memberikan interpretasi terhadap $\mathrm{t}$ hitung, selanjutnya membandingkan $\mathrm{t}_{\text {tabel }}$ pada taraf signifikansi $5 \%\left(\mathrm{t}_{\mathrm{s}}=\right.$ 0,05) dengan $d . f=\mathrm{N}-2$ dari kelompok $\mathrm{N}=24$ maka $d . f=24-2$ $=22$ adalah 2, 074. Dan taraf signifikansi $1 \% \quad\left(\mathrm{t}_{\mathrm{s}}=0,01\right)$ dengan d.f $=\mathrm{N}-2$ dari kelompok $\mathrm{N}=24$ maka $d . f=24-2=22$ adalah 2,819 . Berdasarkan kaidah pengujian:

Jika $t_{\text {hitung }} \geq t_{\text {tabel }}$ maka tolak $\mathrm{H}_{\mathrm{o}}$ artinya signifikan.

Jika $t_{\text {hitung }} \leq \mathrm{t}$ tabel maka terima $\mathrm{H}_{\mathrm{o}}$ tidak signifikan.

Dari hasil nilai konsultasi dengan $t$ tabel dan $t$ hitung, ternyata hasil $t$ hitung lebih kecil dibandingkan dengan nilai $\mathrm{t}$ tabel atau $0,59 \leq 2,074 \leq 2,819$. Dengan demikian hipotesis nihil (Ho) yang ditawarkan diterima. Berarti antara 
media gambar dengan media radiotidak ada perbedaan yang signifikan.

Berdasarkan

hasil

perhitungan yang telah dilakukan, dapat diketahui nilai rata-rata sebesar 72,4. Dari hasil perhitungan nilai siswa pada kelas yang telah dilakukan eksperimen dengan menggunakan media gambar, Nilai rata-rata sebesar 71 dari hasil perhitungan nilai siswa pada kelas yang telah dilakukan ekperimen dengan menggunakan media radio. Jadi, dapat dilihat bahwa mean atau rata-rata tidak terlalu besar dengan selisih sebesar 1,4. Hal ini berarti antara media gambar dengan media radio tidak terdapat perbedaan yang signifikan, maka dapat disimpulkan bahwa dua buah media pembelajaran tersebut hampir sama.

Penggunaan media dapat meningkatkan hasil belajar siswa. Hal ini dapat dibuktikan dengan melihat kriteria ketuntasan minimum (KKM) siswa SMA Tunas Harapan Balaraja sebesar 6,5 pada pembelajaran menulis deskripsi. Berdasarkan hasil yang diperoleh, nilai rata-rata siswa di atas nilai KKM yang telah ditentukan oleh sekolah. Hal ini berarti media gambar dan media radio yang digunakan dalam eksperimen, pada pembelajaran menulis deskripsi dikatakan berhasil, karena dapat meningkatkan hasil belajar. Setelah

dilakukan perhitungan dengan menggunakan rumus uji $t$, diperoleh hasil $t$ hitung sebesar 0,59. Untuk memberikan interpretasi terhadap $\mathrm{t}$ hitung, selanjutnya membandingkan $t_{\text {tabel }}$ pada taraf signifikansi $5 \%\left(\mathrm{t}_{\mathrm{s}}=0,05\right)$ dengan $d . f=\mathrm{N}-2$ dari kelompok $\mathrm{N}$ $=24$ maka $d . f=24-2=22$ adalah 2, 074. Dan taraf signifikansi $1 \%\left(\mathrm{t}_{\mathrm{s}}\right.$
$={ }_{0,01}$ ) dengan $\quad$ d.f $=\mathrm{N}-2$ dari kelompok $\mathrm{N}=24$ maka $d . f=24-2$ $=22$ adalah 2, 819. Atau 0,59 $\leq 2$, $074 \leq 2,819$ maka,Sesuai dengan kaidah pengujian, apabila $t_{\text {hitung }}$ lebih kecil atau sama dengan $t_{\text {tabel }}$, maka terima $\mathrm{H}_{\mathrm{o}}$ artinya tidak signifikan. Bedasarkan hasil pengujian analisis

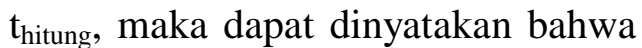
tidak ada perbedaan yang signifikan antara penggunaan media gambar dengan penggunaan media radio terhadap pembelajaran menulis deskripsi. Artinya kedua media tersebut efektif digunakan dalam pembelajaran menulis deskripsi di kelas X SMA TUNAS HARAPAN Balaraja

\section{SIMPULAN}

Berdasarkan hasil kegiatan penelitian di SMA TUNAS HARAPAN Balaraja-Tangerang dan sesuai dengan tujuan yang sudah disampaikan pada bab 1 , selanjutnya yaitu membuat simpulan bahwa media gambar dan media radio dapat meningkatkan hasil belajar. Hal ini dapat dibuktikan bahwa hasil pembelajaran menulis deskripsi dengan menggunakan media gambar diperoleh nilai rata-rata sebesar 72,4 dan hasil pembelajaran menulis deskripsi dengan menggunakan media radio diperoleh nilai rata-rata sebesar 71. Jika dilihat dari kriteria ketuntasan minimum (KKM) di SMA Tunas harapan Balaraja sebesar 6,5 pada pembelajaran menulis deskripsi, hal ini menunjukkan bahwa nilai rata-rata siswa di atas nilai KKM yang telah ditentukan oleh sekolah. Maka dari itu, proses pembelajaran menulis deskripsi dengan menggunakan media gambar maupun proses pembelajaran menulis deskripsi dengan 
menggunakan media radio dikatakan berhasil, karena dapat meningkatkan hasil belajar. Dan kedua buah media pembelajaran tersebut hampir sama, karena jika dilihat dari mean atau rata-rata perbedaannya tidak terlalu besar dengan selisih nilai sebesar 1,4.

Dari hasil pengujian dangan menggunakan rumus $t$ hitung, diperoleh hasil $t$ hitung sebesar 0,59 dan hasil $t$ hitung tersebut, dibandingkan dengan taraf signifikasi $5 \%$ sebesar 2,074, dan taraf signifikasi $1 \%$ sebesar 2,819 atau $0,59 \leq 2,074 \leq 2,819$ dengan degrees of freedom (N-2), dari data kelompok $\mathrm{N}=24$ maka $24-2=22$. Maka sesuai dengan kaidah pengujian, apabila $t_{\text {hitung }}$ lebih kecil atau sama dengan $t_{\text {tabel}}$, maka terima $\mathrm{H}_{\mathrm{o}}$ artinya tidak signifikan. Dengan hipotesis nihil $\mathrm{H}_{\mathrm{o}}$ diterima, maka dapat disimpulkan bahwa tidak ada perbedaan yang signifikan antara kelas X.1 dengan menggunakan media gambar, dengan kelas X.2 dengan menggunakan media radio. Artinya kedua media tersebut efektif digunakan dalam pembelajaran menulis deskripsi di SMA Tunas Harapan Balaraja-Tangerang.

\section{DAFTAR PUSTAKA}

Akhadiah, Sabarti (dkk). 1989. Pembinaan Kemampuan Menulis Bahasa Indonesia. Jakarta: Erlangga.

Arifin, Zaenal. 2009. Evaluasi Pembelajaran. Bandung: PT. Remaja Rosdakarya.

Arikunto, Suharsimi. 2006. Prosedur Penelitian Suatu Pendekatan Praktek. Jakarta: PT. Rineka Cipta.

Arsyad, Azhar. 2007. Media Pembelajaran. Jakarta: PT. RajaGrafindo Persada.

Djuharie, O. Setiawan. 2001. Penduan Membuat Karya Tulis. Bandung: Yrama Widya.

Finoza, Lamuddin. 2008. Komposisi Bahasa Indonesia. Jakarta: Diksi Insan Mulia.

Hamalik, Omear. 2001 Kurikulum Pembelajaran. Bandung: Bumi Aksara.

Hariyadi, Moh. 2009. Statistik Pendidikan. Jakarta: PT. Prestasi Pustakaraya.

Hasani, Aceng. 2005. Ihwal Menulis. Serang: Untirta Press.

Hasan, Iqbal. 2002. Metodologi Penelitian dan Aplikasinya. Jakarta: Ghalia Indonesia.

Ibrahim R, dkk. 2003. Perencanaan Pengajaran. Jakarta: Rineka Cipta.

Keraf, Gorys. 1982. Eksposisi dan Deskripsi. Jakarta: Nusa Indah.

24 | Jurnal Kredo

Vol. 1 No. 2 April 2018 
M.S. Mahsun. 2005. Metode Penelitian Bahasa. Jakarta: PT. Raja Grafindo Persada.

Nazir, Moh. 2005. Metode Penelitian. Bogor Selatan: Ghalia Indonesia.

Rusli, Marah. 2001. Sitti Nurbaya: Kasih Tak Sampai. Jakarta: Balai Pustaka.

Sadiman, Arief S. (dkk). 2007. Media Pendidikan: Pengertian, Pengembangan, dan Pemanfaatanya. Jakarta: PT RajaGrafindo Persada.

Semi, M Atar. 2007. Dasar-dasar Keterampilan Menulis. Bandung: Angkasa.

Semi, M Atar. 2003. Menulis Kreatif. Padang: Angkasa Raya.

Sulaeman, Amir Hamzah. 1985. Media Audio - Visual. Jakarta: PT Gramedia.

Suparno, Mohamad Yunus. 2004. Keterampilan Menulis, Modul 1-6. Jakarta: Universitas Terbuka. Departemen Pendidikan Nasional. 